Abstracta Iranica Abstracta Iranica

Revue bibliographique pour le domaine irano-aryen

Volume 29 | 2008

Comptes rendus des publications de 2006

« Image et statut des femmes dans l'Iran rural : une révolution silencieuse? ». Études rurales, janvierjuin 2006, pp. 151-166.

Azadeh Kian-Thiébaut

(2) OpenEdition

Journals

Édition électronique

URL : http://journals.openedition.org/abstractairanica/33512

DOI : 10.4000/abstractairanica.33512

ISSN : 1961-960X

Éditeur :

CNRS (UMR 7528 Mondes iraniens et indiens), Éditions de l'IFRI

Édition imprimée

Date de publication : 15 mai 2008

ISSN : 0240-8910

Référence électronique

Azadeh Kian-Thiébaut, « «Image et statut des femmes dans I'Iran rural : une révolution silencieuse

?». Études rurales, janvier-juin 2006, pp. 151-166. », Abstracta Iranica [En ligne], Volume 29 | 2008 ,

document 426, mis en ligne le 15 septembre 2008, consulté le 26 septembre 2020. URL : http://

journals.openedition.org/abstractairanica/33512; DOI : https://doi.org/10.4000/abstractairanica.

33512

Ce document a été généré automatiquement le 26 septembre 2020.

Tous droits réservés 


\title{
« Image et statut des femmes dans l'Iran rural : une révolution silencieuse? ». Études rurales, janvier-juin 2006, pp. 151-166.
}

\author{
Azadeh Kian-Thiébaut
}

Ethnologue ayant effectué son travail de terrain au village d'Afzād dans la région de Kermān, l'A. analyse les transformations socioéconomiques du monde rural en Iran de ces dernières décennies et leur impact sur le statut des femmes et sur les représentations qui lui sont associées. L'exode rural, la crise économique et l'influence de la culture urbaine ont transformé l'économie villageoise conduisant à la baisse des revenus issus du travail agricole et du tissage. La vie des femmes a certes été facilitée mais elles ont perdu en indépendance et en responsabilités car aujourd'hui les revenus de l'homme jouent le rôle essentiel dans le budget familial. Pour l'A., l'adoption par les femmes de nouvelles valeurs, la baisse de la fécondité, le travail des femmes ou l'accroissement des soins esthétiques correspondent à un aménagement des traditions chi'ites et locales, avec le soutien des hommes. Avec la valorisation des études, le désir d'une profession salariée dans le secteur public (notamment dans les secteurs de la santé et de l'enseignement) gagne les jeunes filles et leurs parents tandis que les tâches féminines traditionnelles sont dévalorisées. Le travail salarié des femmes devient ainsi une marque de prestige et un important atout sur le marché matrimonial. La partie la plus innovante et intéressante de l'article concerne l'émergence d'un nouveau mode relationnel au sein du couple avec l'homme et la femme qui ne se pensent plus seulement en père et mère mais de plus en plus en époux et épouse. La démonstration est faite à travers l'analyse du changement des critères de beauté féminine qui portent désormais sur l'ensemble du corps et bouleversent les anciens codes de pudeur. Les femmes justifient ces soins par le désir de plaire à leur mari, les hommes se montrent sensibles aux nouveaux canons de la féminité. D'ailleurs, ces derniers passent la majeure partie de leur temps libre chez eux pour bricoler, tandis que les jeunes femmes accèdent de plus en plus à l'espace public grâce à l'éducation et à un emploi salarié. Ces 
femmes rurales, sans être en rupture avec les traditions, contribuent silencieusement à l'évolution de leur statut.

INDEX

Thèmes : 16.1. Iran

\section{AUTEURS}

\section{AZADEH KIAN-THIÉBAUT}

Université Paris VII - Mondes iranien et indien 